УДК 94 (571.5)

КАЛЬМИНА Лилия Владимировна - доктор исторических наук, доцент; ведущий научный сотрудник отдела истории, этнологии и социологии Института монголоведения, буддологии и тибетологии СО РАН (670047, Россия, Республика Бурятия, г. Улан-Удэ, ул. Сахьяновой, 6; kalminal@gтаil.com) ПЛЕХАНОВА Анна Максимовна - доктор исторических наук, доиент; ведущий научный сотрудник отдела истории, этнологии и социологии Института монголоведения, буддологии и тибетологии СО РАН (670047, Россия, Республика Бурятия, г. Улан-Удэ, ул. Сахьяновой, 6; plehanova.am@таil.ru)

\title{
ФОРМИРОВАНИЕ БАНКОВСКОЙ ИНФРАСТРУКТУРЫ В ВЕРХНЕУДИНСКЕ: ЗАКОНОМЕРНОСТИ И ПАРАДОКСЫ
}

\begin{abstract}
Аннотация. Внимание авторов сосредоточено на реконструкции процесса и определении специфики формирования кредитно-финансовой инфраструктуры в крупном торговом городе Западного Забайкалья - Верхнеудинске. Показано, что, несмотря на сложившиеся условия для организации банковских учреждений в городе во второй половине XIX в., их открытие было сопряжено с рядом трудностей. Установлено, что создание разветвленной банковской сети заметно усилило конкуренцию на рынке кредитно-финансовых услуг Верхнеудинска и положительно сказалось на экономике Западного Забайкалья в целом.
\end{abstract}

Ключевые слова: Верхнеудинский общественный банк, Госбанк, Русско-Китайский банк, Верхнеудинское общество взаимного кредита, банковские обороты, Нормальное положение

3 акономерностью в данном контексте является формирование банковской сети в крупном торговом городе Верхнеудинске, где для проведения большинства коммерческих операций требовалась денежная ссуда. Парадоксом стало то, что, несмотря на его официальное признание как «наиболее торгового города в Восточной Сибири» [Экономическое состояние... 1882: 338], его банковская сеть формировалась очень трудно, натыкаясь на препятствия там, где их, казалось бы, быть не должно.

До того, как возникли первые кредитные учреждения, простейшие их функции выполняли ссудо-сберегательные кассы при казначействах, почтово-телеграфных конторах, таможне. С 1769 г. с введением в денежный оборот ассигнаций и разрешением вексельного перевода платежей из Европейской России в Сибирь безналичный расчет начал распространяться в Забайкалье, стали появляться государственные банковские конторы для кредитно-вексельных операций. Рост товарообменных услуг, необходимость снижения затрат на доставку товаров способствовали развитию платы за них нетоварными средствами. В XIX в. местные купцы использовали в расчетах векселя австрийских, французских, немецких и крупных российских торговых домов, а также коммерческих банков (Государственного коммерческого, Нижегородского и Екатеринбургского коммерческих банков, Иркутского сиропитательного дома и др.) [Становление... 2008]. Однако рост объемов международной торговли, проведение ярмарок, увеличение золотодобычи требовали дальнейшего увеличения оборотного капитала, в первую очередь с помощью кредитных операций. И если крупные торговцы могли взять кредит в других городах, то у мелких не было «никакой возможности воспользоваться банковской ссудой под залог недвижимости, товаров или продуктов сельского хозяйства» ${ }^{1}$.

${ }^{1}$ Государственный архив Республики Бурятия (ГАРБ). Ф. 10. Оп. 1. Д. 1038. Л. 11. 
Попытки открыть местное отделение банка предпринимались неоднократно, но часто заканчивались неудачей. Первая такая попытка относится к 1872 г., когда город подал ходатайство об открытии общественного банка. (Такие банки создавались для кредитования мелких ремесленников и лавочников, не имевших достаточной суммы для открытия собственного дела.) К этому времени общественные банки открылись уже во многих сибирских городах. В 1880 г. их число в Сибири достигло 14: восемь в Западной Сибири и шесть в Восточной ${ }^{1}$. Стабильно работали банки в Тюмени, Кургане, Тобольске, Омске [Скубневский, Гончаров 2014: 112]. Успешно функционировали общественные банки и в Забайкалье, своей прибылью подпитывая городской бюджет и отчисляя значительную ее долю на благотворительность $^{2}$. Верхнеудинск же в ответ на свои прошения дважды получил отказ Министерства финансов. Причина заключалась в том, что в уставе будущего кредитного учреждения не содержался пункт о готовности городского общества разделить с банком ответственность перед вкладчиками в случае разорения последнего. А Министерство финансов, обеспокоенное частым банкротством банков, стремилось гарантировать их надежность еще на стадии учреждения, требуя обеспечения «целостности сумм» и отказывая в открытии при малейшем сомнении. Разрешение на учреждение общественного банка Верхнеудинск получил только в 1881 г. после ходатайства генерал-губернатора Восточной Сибири Д.Г. Анучина, просившего министерство не задерживать открытие банков на подведомственной ему территории, которая испытывает в них крайнюю нужду. Тем более что ввиду своей маломощности здешние банки мало влияли на общую картину банковского дела в империи ${ }^{3}$. Однако с таким трудом открывшийся Верхнеудинский общественный банк просуществовал всего 4 года. Столь короткий срок во многом стал результатом принятия Нормального положения, изданного на основании Высочайше утвержденного 26 апреля 1883 г. мнения Государственного совета. Цель Положения была благой: обеспечить стабильность работы общественных банков. Но для Верхнеудинского документ стал роковым.

Принципиальными для деятельности недавно открытого банка были три статьи. Статья 46 требовала, чтобы наличность в кассе городского общественного банка вместе с суммами, помещенными на текущий счет в конторе Госбанка, была не менее $10 \%$ всех обязательств банка - для обеспечения достаточного количества денег на случай требований клиентами возврата вкладов. Статья 42 ограничивала сумму вкладов, векселей и сумм по другим операциям пятикратным превышением собственных капиталов банка вместо ранее допускавшегося десятикратного. Эта, казалось бы, нелогичная мера преследовала цель не допустить возможности для городской власти запустить руку в банковскую кубышку при внесении в качестве учредительного капитала минимально возможной суммы. Наконец, статья 44 разрешала получателю кредита взять не более 1/10 суммы собственного капитала банка 4 . Этим Положение стремилось оградить горожан от ситуации, когда кредиты будут выданы одному-двум крупным торговцам вместо того, чтобы кредитовать массу мелких, для кого, собственно, и создавался общественный банк.

Новые правила сразу поставили под сомнение будущую работу банка. Для уменьшения суммы вкладов до пятикратной величины собственного капи-

\footnotetext{
${ }_{1}^{1}$ Сибирь. 1882. № 1 (3 янв.).

2 ГАРБ. Ф. 10. ОП. 1. Д. 2592. Л. 6, 47, 33, 38, 19, 20, 42.

3 Там же. Д. 352. Л. 1-2.

4 Там же. Д. 401. Л. 21-22; Д. 457. Л. 2.
} 
тала нужно было либо прекратить прием новых вкладов, либо часть вкладов вернуть. Но и отказ банка от приема вкладов, и принудительное их возвращение делали существование кредитного учреждения бессмысленным. Это требование, как и ограничение размеров кредита, по мнению членов правления банка, годилось для крупных банков с капиталами в десятки и сотни тысяч рублей. В Верхнеудинском же банке при общей сумме основного и запасного капиталов в 20 тыс. руб. самый большой кредит не мог превышать 2 тыс. руб. Столь ничтожная сумма никого бы не заинтересовала, и капиталам банка грозило остаться без движения, принося ему больше убытков, чем прибыли 1 . Городская дума просила Министерство финансов отсрочить введение этих статей, особенно в части размеров выдаваемых кредитов, поскольку «торгующих в Верхнеудинске не более 30 лиц, и из них кредитуется в банке не более половины». Министерство пошло ей навстречу, позволив отложить введение правила об ограничении суммы кредита. Пользуясь отсрочкой, банк выдал увеличенные кредиты 25 лицам, которых считал вполне надежными. Но к марту 1886 г. кредитование вернулось к положенной норме 2 .

При анализе работы банка сразу обращает на себя внимание тот факт, что при внешне благополучных цифрах в его работе было несколько нюансов, которые предвещали скорый конец. Капитал банка рос быстро, но главным образом за счет векселей, составлявших до 76\%. Сумма вкладов тоже росла, но значительная их часть были краткосрочными. Вексельный портфель таял, что, казалось бы, свидетельствовало о возвращении векселедателями взятых ссуд. Но на деле суммы взыскания по ним были незначительны ${ }^{3}$. Уже к 1884 г. убытки банка превысили 4 тыс. руб., причем 3 тыс. из них взял город на латание бюджетных дыр, образовавшихся в силу разных обстоятельств 4 . Нормальное положение не смогло оградить банк от «заимствования» денежных сумм городской властью. Последующие 2 года банк также сработал с убытками, которые составили в общей сложности 4937 руб. 88 коп. 5 Это вынудило правление ходатайствовать о закрытии банка. Городская дума поддержала это решение, после чего городской голова Н.А. Шляпкин телеграммой просил министра финансов Н.Х. Бунге согласия на ликвидацию банка6

По стойкому мнению правления банка, причиной его «стеснительности» стало именно Положение об общественных банках, преследующее как раз цель обеспечения стабильности их работы. Но оно было принято «не вовремя». Давно работающие и зарекомендовавшие себя банки уцелели, а молодой Верхнеудинский общественный банк еще не успел обрасти финансовым «жирком».

Следует, однако, отметить, что Верхнеудинский общественный банк не обанкротился, а ликвидировал свои дела. Принципиальная разница заключалась в том, что он рассчитался с вкладчиками, выдав им 63828 руб., а оставшиеся средства (наличные, векселя, имущество) на сумму 19101 руб. 69 коп. передал городской управе. Банковские операции велись весь ликвидационный период - с 1 сентября 1886 по 1 марта 1887 г. [Кальмина 2017: 83].

Впоследствии город не единожды предпринимал попытки основать общественный банк, предполагая использовать в качестве его основного капитала средства запасного городского. Но каждый раз оказывалось, что часть этих

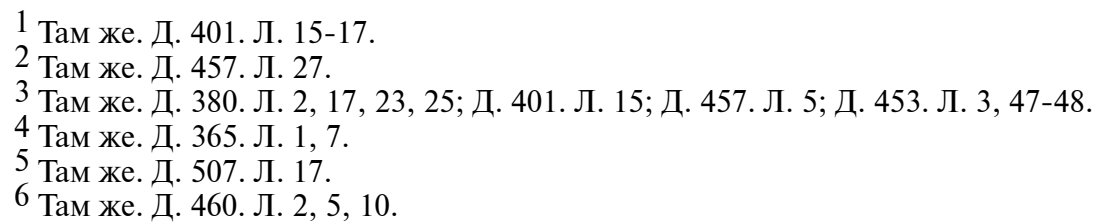


средств уже бесследно исчезла «ввиду разновременных позаимствований» (опасения Министерства финансов оказались не напрасными!), поэтому город неизменно получал отказ 1 .

Столь же неудачной была попытка Верхнеудинска открыть постоянное отделение Государственного банка, хотя во время зимней ярмарки ввиду острой необходимости в городе работало его временное отделение. Впервые оно было открыто в 1894 г. по инициативе управляющего Иркутским отделением банка статского советника Михайловского, «чрез что», как указывалось в печати, «торгующее купечество не встречало ни малейших затруднений по переводу денег и учету векселей» 2 . Уже в следующем году временное отделение банка за 18 операционных дней заработало 9,5 тыс. руб. прибыли и «приобрело симпатии и доверие публики, благодаря приветливому и предупредительному отношению служащих» ${ }^{3}$. Однако открыть постоянное отделение городу так и не удалось даже после проведения Транссибирской магистрали, которая дала стимул росту промышленности, торговли и промыслов и сделала учреждение банка еще более необходимым. Решение вновь подать прошение городская дума приняла в 1902 г. Но министр финансов В.Н. Коковцов, опираясь на мнение Приамурского генерал-губернатора 4 , считавшего, что оснований для его открытия мало, в просьбе отказал 5 . Городская дума вернулась к этому вопросу в 1906 г. В прошении для придания городу значимости городские власти искусственно «вырастили» его население до 25 тыс. чел., хотя однодневная перепись 7 октября 1907 г. зафиксировала только 14,5 тыс. [Улан-Удэ - 350... 2016: 165]. Однако городу вновь было отказано под предлогом того, что в империи имеется еще много пунктов, которые по торговому своему значению ощущают более настоятельную необходимость в открытии банка, чем г. Верхнеудинск. Вновь парадокс: в ходатайстве было отказано крупному торгово-промышленному центру Забайкалья, который имел все основания для его удовлетворения. Его годовые обороты к этому времени выросли до 18 млн руб., а две ярмарочные недели давали временному отделению Госбанка до 10 тыс. руб. «чистой пользы» 6 .

Крупнейшее финансовое учреждение - Русско-Китайский банк, созданное под патронажем Министерства финансов Российской империи и раскинувшее сеть своих отделений и представительств не только по всей стране от Владивостока до Санкт-Петербурга, но и за рубежом - в Китае, Японии, Франции, открыло свое отделение в г. Верхнеудинске в 1898 г. Идея организации финансово-кредитного института в крупном торговом центре Забайкалья, подкрепленная возможностью получения банком хорошей прибыли от кредитно-финансового посредничества в городе, известном своими торговыми традициями, была безоговорочно поддержана городскими властями и с большим энтузиазмом воспринята местными торговцами и предпринимателями. Именно интересы последних диктовали открытие отделения банка, обладающего достаточными ресурсами для кредитования в крупных размерах, имеющего развитую инфраструктуру, технически оснащенного, располагающего

1 ГАРБ. Ф. 10. ОП. 1. Д. 259. Л. 1, 52, 57, 61-62, 64.

2 Забайкальские областные ведомости. 1894. Прибавление к № 16 официальной части.

3 Забайкальские областные ведомости. 1895. Приложение к № 11 неофициальной части.

4 К сожалению, точно установить, чье именно мнение стало решающим для В.Н. Коковцова, не удалось. За время, прошедшее с подачи прошения городской думой до ответа министра финансов, в Приамурье сменились два генерал-губернатора: Д.И. Суботич и Е.И. Алексеев.

5 ГАРБ. Ф. 10. ОП. 1. Д. 1684. Л. 1, 11.

6 Там же. Л. 20, 15, 12. 
профессиональным кадровым составом и широкой географией межбанковских связей.

Филиал банка развернул масштабную и хорошо организованную финансовую деятельность, предоставляя своим клиентам широкий спектр услуг: учет векселей; выдачу ссуд (срочных и до востребования) под залог товаров, векселей, процентных бумаг, торговых обязательств и коносаментов; операции с процентными бумагами; открытие и обслуживание текущих счетов и вкладов, проверку векселей, отправление и прием денежных переводов. Отделение, согласно положениям устава банка, оказывало своим клиентам и нетипичные для финансово-кредитного учреждения услуги, такие как страхование движимого имущества ${ }^{1}$, для чего банк в 1908 г. заключил партнерское соглашение со страховым обществом «Саламандра» [Плеханова, Ширапов 2019: 209]. Это направление деятельности имело большое значение, т.к. основную часть клиентуры Верхнеудинского филиала составляли предприниматели, для которых возможность страхования имущества и товаров представляла немалый интеpec.

Экономический кризис начала века и поражение в Русско-японской войне негативно сказались на деятельности Верхнеудинского отделения. Заметный спад показали многие банковские операции: всего за год (с 1907 по 1908 г.) учет векселей сократился более чем на 25\%, выдача срочных ссуд - на 50\%. Однако последующий экономический подъем благотворно отразился на показателях Верхнеудинского отделения Русско-Китайского банка, который в 1910 г. после реорганизации и слияния с Северным банком стал называться РусскоАзиатским. Общий оборот отделения в 1911 г. составлял 65,6 млн руб., в 1912 г. - 72,1 млн руб., в 1913 г. - 58 млн руб. ${ }^{2}$ Снижение оборотов отделения в 1913 г. во многом стало следствием осторожной политики банка, предусматривавшей кредитование клиентов по завышенным процентным ставкам.

В ситуации, когда у предпринимателей, владевших небольшим бизнесом, возникали проблемы с получением кредита, закономерным стало возвращение к идее создания в Верхнеудинске собственного финансово-кредитного учреждения, чьими услугами могли бы пользоваться широкие слои городского населения. Инициативу вновь проявили городские власти, предложив создать общество взаимного кредита - товарищество со складочным капиталом из добровольных взносов членов и ответственностью каждого участника по долгам «в размере открытого ему кредита, превышающего в десять раз его членский взнос и определяющего величину его долевого участия в прибыли» [Грузицкий 2002: 67]. (К 1908 г. сеть подобных учреждений охватывала всю территорию страны - от Владивостока до Варшавы.) Большая часть подготовительной работы по созданию ОВК в Верхнеудинске была проведена городским головой И.В. Титовым, справедливо полагавшим, что верхнеудинцы могут только «читать вывески (банков) и сетовать на то, что богатому человеку везде есть кредит, а для бедного всюду нет» [Кальмина 2017: 84]. И.В. Титов разработал проект устава будущего общества, составил список его потенциальных членов и заручился поддержкой со стороны уездного начальства, которое дало согласие на обсуждение вопроса об организации общества [Плеханова, Ширапов 2020: 51]. Парадокс ситуации заключался в том, что, хотя грамотно спланированный и тщательно продуманный проект был «весьма сочувственно» встречен верхнеудинскими торговцами, в 1911 г., спустя почти 3 года, общество все

\footnotetext{
1 Устав русско-китайского банка. Утв. 10 декабря 1895 г. СПб. 1895. С. 14.

2 Российский государственный исторический архив (РГИА). Ф. 630. Оп. 1. Д. 276. Л. 3, $21,38,56$.
} 
еще было в разряде «нарождающихся». По-видимому, его устав, предусматривавший вступительный взнос наличными каждого его члена в размере $10 \%$ от суммы «допущенного кредита», делал затруднительным вступление в общество сразу 50 чел., необходимых для его учреждения. А для мелких предпринимателей внести сразу 100 руб. в качестве вступительного взноса при минимальной сумме кредита в 1 тыс. руб. было делом нелегким ${ }^{1}$. Однако в конечном итоге это не помешало Верхнеудинскому ОВК очень быстро сформировать свою клиентскую базу из представителей разных социальных групп (торговцев, предпринимателей, служащих, сельских хозяев, лиц свободных профессий и др.) и занять свою нишу на финансовом рынке Западного Забайкалья. Наиболее востребованными операциями в ВОВК были кредитование под залог товаров и товарных документов, учет векселей, переводы денежных средств. Уже в 1912 г., через год после открытия, общий оборот общества составил солидную сумму - более 10 млн руб. ${ }^{2}$

Помимо вышеперечисленных банковских и кредитных учреждений, финансовые услуги в Верхнеудинске оказывало отделение Сибирского торгового банка, открытое в 1898 г. С 1895 г. в городе функционировала сберегательная касса при почтово-телеграфной конторе. Действовали агентства Нижегородско-Самарского Земельного банка, Ярославско-Костромского земельного банка, других кредитных учреждений и банкирских домов 3 .

Таким образом, на рубеже XIX - XX вв. парадоксальная ситуация разрешилась закономерным итогом. Рост числа кредитно-финансовых учреждений, отличающихся организационными формами, видами и объемами операций, заметно усилил конкуренцию на рынке банковских услуг Верхнеудинска, что положительно сказалось на предпринимательской активности горожан и в целом на экономике Западного Забайкалья.

Статья подготовлена в рамках государственного задания (проект ХII.191.1.1. «Трансграничье России, Монголии и Китая: история, культура, современное общество», номер госрегистрации № АAAA-A17-117021310269-9).

\section{Список литературы}

Грузицкий Ю.Л. 2002. Общества взаимного кредита в Российской империи (история появления и этапы развития). - Финансы и кредит. № 13. С. 66-72.

Кальмина Л.В. 2017. Верхнеудинский общественный банк в контексте финансовой политики самодержавия. - Известия Иркутского государственного университета. Сер. Политология. Религиоведение. Т. 21. С. 79-85.

Плеханова А.М., Ширапов А.А. 2019. Верхнеудинское отделение РусскоКитайского банка: направления, специфика и результаты деятельности в условиях трансграничья. - Власть. Т. 27. № 3. С. 206-211.

Плеханова А.М., Ширапов А.А. 2020. Верхнеудинское общество взаимного кредита: история создания и начальный этап деятельности в условиях трансграничья (1911-1913). - Гуманитарный вектор. Т. 15. № 3. С. 48-56.

Скубневский В.А., Гончаров Ю.М. 2014. Города Западной Сибири во второй половине XIX - начале XX в.: Население. Экономика. Застройка и благоустройство. Барнаул: ИП Колмогоров И.А. 252 с.

\footnotetext{
1 ГАРБ. Ф. 10. ОП. 1. Д. 2236. Л. 1, 3, 6.

2 Там же. Ф. 282. ОП. 1. Д. 177. Л. 50.
}

3 Национальный банк по Республике Бурятия. - Центральный банк Российской Федерации. Официальный сайт. Доступ: http://old.cbr.ru/tubr/sib-o/bur-r/history/ (проверено 15.06.2020). 
Становление банковского сектора в Бурятии (к 150-летию Банка России). Вестник Банка России. 2008. № 70. Доступ: https://cbr.ru/about_br/publ/vestnik/ year/2008/ (проверено 24.08.2020).

Улан-Удэ - 350: история и современность. В 2 т. Т. 1. ХVII - начало ХХ в. 2016. Иркутск: Оттиск. 372 с.

Экономическое состояние городских поселений Сибири. 1882. СПб: Изд. хозяйственного департамента МВД. 442 с.

KALMINA Liliya Vladimirovna, Dr.Sci. (Hist.), Associate Professor; Leading Scientific Researcher of the Department of History, Ethnology and Sociology, Institute for Mongolian, Buddhist and Tibetan Studies, Siberian Branch of Russian Academy of Sciences (6 Sakhyanova St, Ulan-Ude, Republic of Buryatia, Russia, 670047; kalminal@gmail.com)

PLEKHANOVA Anna Maksimovna, Dr.Sci. (Hist.), Associate Professor; Leading Scientific Researcher of the Department of History, Ethnology and Sociology, Institute for Mongolian, Buddhist and Tibetan Studies, Siberian Branch of Russian Academy of Sciences (6 Sakhyanova St, Ulan-Ude, Republic of Buryatia, Russia, 670047; plehanova.am@mail.ru)

\title{
THE DEVELOPING OF BANK INFRASTRUCTURE IN VERKHNEUDINSK: THE REGULARITIES AND PARADOXES
}

\begin{abstract}
The authors' attention is focused on the reconstruction of the process and determination of the specifics of the formation of the credit and financial infrastructure in the large commercial city of Western Transbaikalia - Verkhneudinsk. The authors show that, despite the prevailing conditions for the organization of banking institutions in the city in the second half of the $19^{\text {th }}$ century, their opening was associated with a number of difficulties. The creation of an extensive banking network has significantly increased competition in the market of credit and financial services of Verkhneudinsk and had a positive effect on the economy of Western Transbaikalia as a whole.
\end{abstract}

Keywords: Verkhneudinsk Public Bank, State Bank, Russo-Chinese Bank, Verkhneudinsk Mutual Credit Society, bank turnover, Normal Regulations 